\title{
Development and In Vivo Evaluation of Ziyuglycoside I-Loaded Self-Microemulsifying Formulation for Activity of Increasing Leukocyte
}

\author{
Yongai Xiong, ${ }^{1,2}$ Ya Zou, ${ }^{1}$ Li Chen, ${ }^{1}$ Yingshu $\mathrm{Xu}^{1},{ }^{1}$ and Sen Wang ${ }^{1}$
}

Received 13 September 2018; accepted 14 January 2019; published online 5 February 2019

\begin{abstract}
Ziyuglycoside I ( $\mathrm{ZgI})$, a major effective ingredient of Sanguisorba officinalis L, has shown good activity in increasing leukocyte of myelosuppression mice. However, oral ZgI therapy has been deterred by poor bioavailability because of its low aqueous solubility and permeability. Our study was to develop ZgI-loaded self-microemulsifying drug delivery system (SMEDDS) and evaluate its intestinal absorption, and pharmacokinetic and pharmacodynamic activity for increasing leukocyte. The formulation was designed and optimized by measuring the equilibrium solubility of $\mathrm{ZgI}$ in different vehicles and the pseudoternary phase diagram. Further, morphology, particle size, stability, in vitro release, in situ single-pass intestinal perfusion (SPIP), in vivo activity, and in vivo pharmacokinetic (PK) of ZgI-SMEDDS were charactered or studied. Optimized formulations for in vitro dissolution were Obleique CC497, Tween-20, and Transcutol HP with a proportion of 0.25/0.45/0.30 via D-optimal mixture design. Results showed that the solubility of $\mathrm{ZgI}$ was enhanced up to $23.93 \mathrm{mg} / \mathrm{g}$ and its average particle size was $207.92 \pm 2.13 \mathrm{~nm}$. The release of $\mathrm{ZgI}$ had been greatly improved by the SMEDDS. In SPIP, the intestinal absorption of SMEDDS was much better than plain ZgI. In PK, we found the oral bioavailability of ZgI-SMEDDS was 6.94-fold higher absolute bioavailability $(21.94 \pm 4.67) \%$ than $\mathrm{ZgI}(3.16 \pm 0.89) \%$. The most important was that the mice WBC of ZgI-SMEDDS group was significantly higher than that of the ZgI group. Our study suggested that SMEDDS could increase the solubility of ZgI, which was beneficial to improve oral bioavailability and enhance biological activity.
\end{abstract}

KEY WORDS: ziyuglycoside I; SMEDDS; bioavailability; solubility.

\section{INTRODUCTION}

Clinically, the bone marrow of cancer patients are severely damaged by multiple chemoradiotherapy or large doses of chemotherapy drugs, which usually lead to toxic effects(1,2), such as the myelosuppression which is the most frequent and serious one. Once patients suffer from myelosuppression, they have to bear great pain and heavy economic burdens which are caused by leukopenia, neutropenia, anemia, and so on (3). What's more, doctors have to change the CRT schedule or reduce the dose of chemotherapeutic agents. So, protecting the bone marrow and increasing hemocyte (especially the WBC) counts of peripheral blood are very important for tumor patients to undergo chemoradiotherapy and improve their life quality.

Our previous research showed that $\mathrm{ZgI}$ was the main active ingredient of Sanguisorba officinalis (4-6). It is a kind of

\footnotetext{
${ }^{1}$ School of Pharmacy, Zunyi Medical University, West No. 6 Xuefu Road, Xinpu District, Zunyi, 563000, Guizhou, People's Republic of China.

${ }^{2}$ To whom correspondence should be addressed. (e-mail: 625221174@qq.com)
}

pentacyclic triterpenoid saponin, as its chemical structure is shown in Fig. 1. It can promote the proliferation of hematopoietic stem cells (HSCs) in mouse bone marrow and increase the number of hemocytes in mouse peripheral blood, which is important to alleviate the side effects of myelosuppression induced by anticancer drug or radiation (7-9). ZgI is type 4 drug in BCS; it is hardly soluble in water, which has become a major factor limiting its oral bioavailability.

The self-microemulsifying drug delivery system (SMEDDS) is a transparent, homogeneous solution composed of an oil phase, a surfactant, a cosurfactant, and a drug. It can spontaneously emulsify to form microemulsion with particle size $10-100 \mathrm{~nm}$ in the aqueous phase at ambient temperature and mild agitation (10), which is important to enhance the solubility and oral bioavailability of poorly water-soluble or fat-soluble drugs $(11,12)$. SMEDDS can be absorbed by the lymphatic pathway, which can reduce the first-pass metabolism of drugs in the liver and the decomposition of drugs by gastrointestinal enzymes $(13,14)$. Part of the components of SMEDDS can inhibit the catalysis of intestinal cytochrome P450 and the efflux of P-gp to drugs, such as Cremophor EL, Tween-80, caprylic acid and citric acid, Labrasol, Myrj 52, Brij 30, polyethylene glycol (PEG) 400, and PEG 20000 (15-17). 


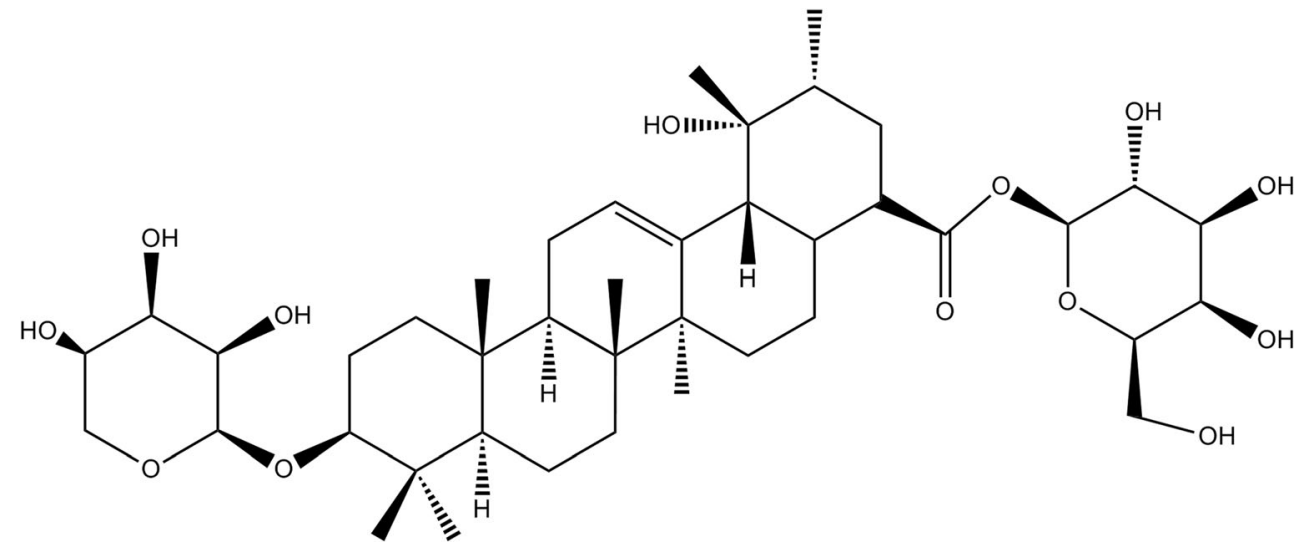

Fig. 1. The chemical structure of $\mathrm{ZgI}$

In this paper, we tried to develop an oral selfmicroemulsion of $\mathrm{ZgI}$, which may be effective to improve the solubility, in vivo release, and gastrointestinal absorption of $\mathrm{ZgI}$. In short, we intended to enhance the bioavailability and activity of $\mathrm{ZgI}$ for increasing WBC.

\section{MATERIALS AND METHODS}

\section{Chemicals and Reagents}

$\mathrm{ZgI}$ was extracted and purified in the lab. $\mathrm{ZgI}$ Reference (lot number MUST-17022502, mass fraction 99.47\%) was purchased from Chengdu Pfizer Biotech Co., Ltd., China. Labrafil M 1944CS, Obleique CC497, Labrasol, and Transcutol $\mathrm{P}$ were purchased from France Jiafa Lions; medium-chain triglycerides (MCT) Mic acid ester, isopropyl myristate (IPM), oleic acid, ethyl oleate, and isopropyl palmitate (IPP) were purchased from Shanghai Chuxing Chemical Co., Ltd.; castor oil, Tween20, Tween-80, Tween-85, PEG-600,PEG-200, and PEG-400 were purchased from Chengdu Kelon Chemical Reagent Factory; and all other chemicals and reagents used were of HPLC grade.

\section{Animals}

SPF Kunming (KM), 우/ð', weighing 20-25 g, were purchased from Laboratory Animal Center of Zunyi Medical University (certificate No. SCXK(Qian) 2013-0006). SPF rats, 우/ð’, weighing $220 \pm 20 \mathrm{~g}$ were purchased from the Third Military Medical University of the People's Liberation Army (Grant No. scxk(army)2012-0011). Mice or rats were housed in normal cages and 12-h light/dark cycle (6.30 am to $6.30 \mathrm{pm})$.

\section{Preparation of SMEDDS}

\section{Determination of Equilibrium Solubility}

The equilibrium solubility of $\mathrm{ZgI}$ was measured in various oils, surfactants, and cosurfactants. $\mathrm{ZgI}$ was excessively added into gcentrifuge tubes containing $2 \mathrm{~g}$ of a vehicle (oil, surfactant, or cosurfactants), and the mixtures were stirred using thermostatic oscillator for $72 \mathrm{~h}$ at $37^{\circ} \mathrm{C}$ and $150 \mathrm{r} /$ min. After shaking, the mixtures were centrifuged at
$8000 \mathrm{rpm}$ for $8 \mathrm{~min}$ and supernatants were filtrated using Millipore filter $(0.22 \mu \mathrm{m})$. The $\mathrm{ZgI}$ concentration was determined using a HPLC.

\section{Preliminary SMEDDS Preparation}

Solubility and pseudoternary phase diagram are usually used to select optimal formulations. According to the equilibrium solubility results of $\mathrm{ZgI}$ in different vehicles, the desired oil, surfactant, and cosurfactant which had the highest solubility to $\mathrm{ZgI}$ would be selected. Then the proportion range of oil, surfactant, and cosurfactant were set according to lipidic formulation classification system (oil, 10-50\%; surfactant and cosurfactant, $0-80 \%$ ) and the solubility test in SMEDDS and superimposed ternary phase diagrams. So the contents of the surfactant, cosurfactant, and oil were in the ranges of $10-50 \% w / w$ of each excipient (18). The solubility of $\mathrm{ZgI}$ in various mixtures was investigated. The resulting mixtures were subsequently titrated with water under moderate agitation at ambient temperature. SMEDDS were characterized on the basis of appearance, emulsification time, droplet size, and solubility of ZgI. All formulations were prepared in triplicate. The pseudoternary phase diagrams were designed using OriginPro10 for Windows (OriginLab Corporation, USA).

\section{Design of Experiments}

The D-optimal mixture design of a three-factor, twolevel SMEDDS formulation was performed using design of experiments (DoE) to determine the individual effects and interaction effects of excipient concentration on the solubility of $\mathrm{ZgI}$ in SMEDDS and the particle size of dilute SMEDDS. Obleique CC497 (factor A) concentrations ranged from 5 to $25 \%$, Tween-20 (factor B) concentrations ranged from 45 to $65 \%$, and Transcutol HP (factor C) concentrations ranged from 10 to 30\%. The Design Expert 8.0.4.1 software was used to study the effect of these formula variables (factors A-C) on the dependent variable ( $Y_{1}$ : solubility of $\mathrm{ZgI}$ in SMEDDS and $Y_{2}$ : particle size of diluted SMEDDS). Twenty experiments were randomly designed by software and repeated two times to improve predictability. All experiments were kept at $100 \%$ batch size. 


\section{Characterization of SMEDDS}

The particle size, polydispersity index (PDI), and zeta potential of optimized SMEDDS were measured by dynamic light scattering using a 90Plus PALS laser particle size analyzer (Brughaven, USA). SMEDDS diluted 200-fold was transferred to a standard cuvette at $25^{\circ} \mathrm{C}$, and measured with a fixed angle of $90^{\circ}$. The software was used to analyze the average particle size, PDI, and zeta potential. Each sample was analyzed in triplicate.

\section{Stability Test}

The ZgI-loaded SMEDDS were put in small plastic bottles and stored in a stability chamber (SHH-500SD, ShanghaiZuocheng Co., Ltd., Shanghai, China). $25^{\circ} \mathrm{C} / 60 \%$ $\mathrm{RH}$ and $40^{\circ} \mathrm{C} / 75 \% \mathrm{RH}$ for 3 months were set to study the stability. Samples were taken out at $0,1,2$, and 3 months for analysis, respectively (19).

\section{Drug-Excipients Compatibility Studies}

Optimized liquid SMEDDS were converted in solid by using the lyophilizer (Labconco, FreeZone5L, USA) and further characterized by Fourier transform infrared (FTIR) spectroscopy, differential scanning calorimetry (DSC), transmission electron microscopy (TEM), and particle size analysis.

FTIR Spectroscopy. The IR spectra were recorded on the FTIR (Thermo Scientific, FTIR model IS5, USA) by using a potassium bromide pressed-disk method. The scanning range was $450-4000 \mathrm{~cm}^{-1}$.

DSC Analysis. The physical state of $\mathrm{ZgI}$ in SMEDDS was characterized by the DSC (Seiko, EXSTAR 6000, Japan). The samples (about $5.00 \mathrm{mg}$ ) were placed in standard aluminum pans and the air was used as $\mathrm{N}_{2}$. All samples were scanned at a temperature ramp speed of $20^{\circ} \mathrm{C} / \mathrm{min}$ and the heat flow was set from 25 to $250^{\circ} \mathrm{C}$.

TEM. ZgI-SMEDDS were diluted 200 times with triple distilled water and $2 \%$ phosphotungstic acid solution was added and mixed by slightly shaking for $1 \mathrm{~min}$. One drop of diluted sample was deposited on a carbon-coated copper grid and observed under the TEM.

\section{In Vitro Drug Release}

ZgI SMEDDS and ZgI were poured into No.0 capsule, respectively. The drug release was performed using shaking water bath operated at $(37.0 \pm 0.5){ }^{\circ} \mathrm{C}$ at $50 \pm 1$ strokes $/ \mathrm{min}$ in $500 \mathrm{~mL}$ of dissolution medium containing $0.1 \% \mathrm{w} / \mathrm{v}$ hydrochloric acid. Samples were taken at 10, 20, 30, 45, 60, 90, and $120 \mathrm{~min}$ at different time intervals and maintained sink condition with $1 \mathrm{~mL}$ of fresh medium, then filtered by $0.22 \mu \mathrm{m}$ microporous membrane. The cumulative percentage drug release was analyzed by the validated HPLC method.
In situ Single Pass Intestinal Perfusion

The single-pass intestinal perfusion (SPIP) studies of ZgI-SMEDDS were carried out in Sprague Dawley (SD) rats. Twelve rats were randomly divided into two groups ( $\mathrm{ZgI}$ and ZgI-SMEDDS) of six rats each and were housed in IVC animal house and lighted on a regular 12-h light-dark cycle. The methods for the SPIP studies were carried out according to references $(20,21)$. Briefly, $10 \%$ chloral hydrate $(4.0 \mathrm{~mL} /$ $\mathrm{kg}$ ) was i.p-injected to anesthetize rats; then, rats were placed on a heating operating table to maintain a body temperature of $37^{\circ} \mathrm{C}$. After the loss of pain reflex, rats' abdomen were opened and a midline longitudinal incision $(3-4 \mathrm{~cm}$ ) was carefully made; then, a $10-15 \mathrm{~cm}$ of the jejunum was isolated and catheterized at both ends with plastic tubing. Thirtyseven degree Celsius saline solution was firstly used to clear the segment for $15 \mathrm{~min}$, then drug perfusion solution which contained $100 \mathrm{mg} / \mathrm{mL} \mathrm{ZgI}$ (in ZgI Krebs-Rings solution and ZgI-SMEDDS) and $100 \mu \mathrm{g} / \mathrm{mL}$ phenol red (marker) was pumped into jejunum via peristaltic pump (Shanghai Huxi Analytical Instrument Factory Co., Ltd.) at a rate of $0.2 \mathrm{~mL} /$ min. When the steady state reached after about $30 \mathrm{~min}$, perfused samples from the outlet should be collected on ice every $15 \mathrm{~min}$ for $150 \mathrm{~min}$. Samples were immediately stored at $-20^{\circ} \mathrm{C}$ until analysis. At the end of the experiment, the perfused intestinal segment was measured without stretching and finally the animal was euthanized. The melted samples were centrifuged at $10,000 \mathrm{rpm}$ for $10 \mathrm{~min}$. A $10 \mu \mathrm{L}$ aliquot of the supernatant was injected into the HPLC system. The absorption rate constant $\left(K_{\mathrm{a}}\right)$, apparent permeability coefficients $\left(P_{\text {app }}\right)$ and drug absorption percentage $(A \%)$ were calculated as the following formulas:

$$
V_{\text {in }}=m_{\text {in }} / \rho_{\text {in }} V_{\text {out }}=m_{\text {out }} / \rho_{\text {out }}
$$

$$
\begin{aligned}
& A \%=\left(1-\frac{C_{\text {out }}}{C_{\text {in }}} \times \frac{Q_{\text {out }}}{Q_{\text {in }}}\right) \times 100 \% \\
& K_{a}=\left(1-\frac{C_{\text {out }}}{C_{\text {in }}} \times \frac{Q_{\text {out }}}{Q_{\text {in }}}\right) \times \frac{Q}{V} \\
& \mathrm{P}_{\text {app }}=\frac{-Q \times \ln \left[\frac{C_{\text {out }} \times Q_{\text {out }}}{C_{\text {in }} \times Q_{\text {in }}}\right]}{2 \pi \mathrm{rl}}
\end{aligned}
$$

where $m_{\text {in }}$ is the weight of the inlet solution, $m_{\text {out }}$ is the weight of the exiting solution, $\rho_{\text {in }}$ is the density of the inlet solution, $\rho_{\text {out }}$ is the density of the exiting solution, $V_{\text {in }}$ is the volume of the inlet solution, $V_{\text {out }}$ is the volume of the exiting solution, $Q$ is the flow rate $(\mathrm{mL} / \mathrm{min})$ of the inlet solution, $C_{\text {in }}$ is the concentration $(\mu \mathrm{g} /$ $\mathrm{mL}$ ) of the drug in the inlet solution, $C_{\text {out }}$ is the concentration $(\mu \mathrm{g} / \mathrm{mL})$ of the drug in the exiting solution, $V$ is the volume of the perfused segment $(\mathrm{mL}), l$ is the length of the intestinal segment $(\mathrm{cm})$, and $r$ is the radius of the intestinal segment $(\mathrm{cm})$.

The $A \%, K_{\mathrm{a}}$, and $P_{\text {app }}$ values of $\mathrm{ZgI}$ were calculated from 45 to $75 \mathrm{~min}$ to 165 to $195 \mathrm{~min}$ in each intestine segment, and the mean value of $A \%, K_{\mathrm{a}}$, and $P_{\mathrm{app}}$ of $\mathrm{ZgI}$ at five time periods were calculated. The average value was used as the actual $A \%, K_{\mathrm{a}}$, and 
Table I. Results of the Solubility of $\mathrm{ZgI}$ in Various Excipients $(\bar{x} \pm S$,

\begin{tabular}{lll}
\multicolumn{2}{c}{$n=3)$} & \\
\hline Excipients & & Solubility $(\mathrm{mg} / \mathrm{g})$ \\
\hline Oil & Labrafil M 1944CS & $1.79 \pm 0.18$ \\
& Obleique CC497 & $2.87 \pm 0.57$ \\
& Castor Oil & $0.88 \pm 0.09$ \\
& IPP & $0.56 \pm 0.03$ \\
& Oleic Acid & $2.63 \pm 0.15$ \\
& MCT & $0.45 \pm 0.01$ \\
Surfactant & IPM & $0.52 \pm 0.01$ \\
& Ethyl Oleate & $0.44 \pm 0.01$ \\
& Labrasol & $1.40 \pm 0.14$ \\
& Tween-20 & $4.23 \pm 0.33$ \\
Cosurfactant & Tween-85 & $1.43 \pm 0.13$ \\
& Tween-80 & $1.55 \pm 0.19$ \\
& PEG-400 & $8.58 \pm 0.59$ \\
& PEG-600 & $7.91 \pm 0.72$ \\
& PEG-200 & $9.13 \pm 0.61$ \\
& Transcutol P & $9.75 \pm 0.53$
\end{tabular}

$P_{\text {app }}$ value of the intestine segment. SPSS22.0 statistical software was used to analyze the results by one-way ANOVA.

\section{In Vivo Activity Study}

Mice were randomized according to their body weight into four experimental groups after 3 days of acclimatization: control group, cyclophosphamide (CP) group, ZgI-SMEDDS group (10 mg/kg, respectively), and $\mathrm{ZgI}$ group $(10 \mathrm{mg} / \mathrm{kg}$, respectively). Except the control group, mice in other groups were injected intraperitoneally with a single dose of $\mathrm{CP}$ $(150 \mathrm{mg} / \mathrm{kg}, 0.2 \mathrm{~mL} / 10 \mathrm{~g})$ on day 0 and the control group received an equal volume of saline correspondingly. Immediately after $\mathrm{CP}$ treatment, mice were orally administrated $\mathrm{ZgI}-$ SMEDDS and $\mathrm{ZgI}$. The normal and $\mathrm{CP}$ groups received an equivalent volume of distilled water, once a day for six consecutive days. On day 6, the blood from eye vein was collected and placed into a lavender top collection tube containing EDTA and kept at ambient temperature. WBC was measured by a cell counter (Bayer Advia 120, Sysmex,
Table II. D-Optimal Mixture Design and Results

\begin{tabular}{llllll}
\hline No. & $X_{1} / \mathrm{g}$ & $X_{2} / \mathrm{g}$ & $X_{3} / \mathrm{g}$ & $Y_{1} / \mathrm{mg} \mathrm{g}^{-1}$ & $Y_{2} / \mathrm{nm}$ \\
\hline 1 & 0.25 & 0.57 & 0.22 & 24.09 & 208.80 \\
2 & 0.05 & 0.53 & 0.18 & 23.21 & 105.38 \\
3 & 0.05 & 0.65 & 0.30 & 24.54 & 122.12 \\
4 & 0.13 & 0.45 & 0.22 & 22.10 & 164.08 \\
5 & 0.25 & 0.57 & 0.22 & 25.78 & 211.02 \\
6 & 0.25 & 0.57 & 0.22 & 26.17 & 251.97 \\
7 & 0.05 & 0.52 & 0.30 & 22.88 & 155.35 \\
8 & 0.25 & 0.45 & 0.30 & 23.93 & 207.92 \\
9 & 0.13 & 0.45 & 0.22 & 22.98 & 142.73 \\
10 & 0.23 & 0.55 & 0.12 & 20.78 & 255.37 \\
11 & 0.17 & 0.53 & 0.30 & 23.34 & 197.59 \\
12 & 0.17 & 0.64 & 0.18 & 23.26 & 147.95 \\
13 & 0.13 & 0.45 & 0.22 & 22.15 & 174.81 \\
14 & 0.05 & 0.45 & 0.10 & 14.68 & 281.48 \\
15 & 0.05 & 0.65 & 0.17 & 23.46 & 102.58 \\
16 & 0.13 & 0.57 & 0.10 & 22.96 & 508.41 \\
17 & 0.25 & 0.65 & 0.10 & 18.21 & 268.24 \\
18 & 0.18 & 0.65 & 0.30 & 22.79 & 110.79 \\
19 & 0.25 & 0.45 & 0.10 & 23.38 & 250.64 \\
20 & 0.13 & 0.57 & 0.10 & 21.66 & 469.49 \\
\hline
\end{tabular}

Kobe, Japan) at times up to $12 \mathrm{~h}$ after blood collection. The experimental protocol was approved by the Animal Ethics Committee for animal experimentation of Zunyi Medical University (Ethic numbers (2018)2-030).

\section{Pharmacokinetic Studies}

The PK studies of $\mathrm{ZgI}$ were carried out in SD rats (male and female). One week after the SD rats were fed adaptively, they were randomly divided into three groups according to their body weight, i.e., the Zg I group, the ZgI-SMEDDS group, and the ZgI-intravenous (i.v) group each containing six animals. After being fasted for $12 \mathrm{~h}$, the $\mathrm{ZgI}$ group of animals received oral Tween-20 solution of $\mathrm{ZgI}(20 \mathrm{mg} / \mathrm{kg})$ and $\mathrm{ZgI}-\mathrm{SMEDDS}$ (25 $\mathrm{mg} / \mathrm{kg}$, equivalent to free $\mathrm{ZgI}$ ). Animals in the ZgI-i.v group were administered with i.v Tween-20 solution of $\mathrm{ZgI}$ ( $2 \mathrm{mg} / \mathrm{kg}$, equivalent to free $\mathrm{ZgI}$ ).
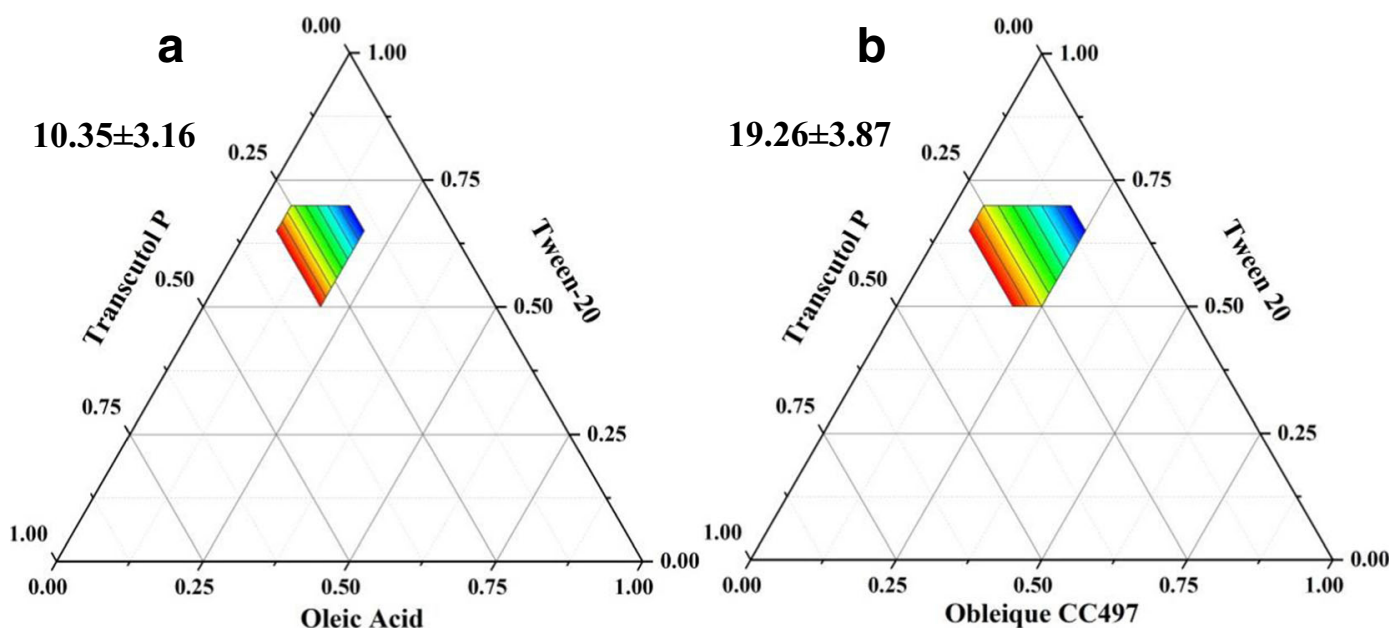

Fig. 2. Ternary phase diagram. a Oleic acid-Tween-20-Transcutol P. b Obleique CC497-Tween-20-Transcutol P. The colorized regions represent the microemulsion phase 
Table III. The Regression Analysis Results of the Experiment

\begin{tabular}{lllllll}
\hline Response & Model & $S$ & $r^{2}$ & Adjusted $r^{2}$ & Predicted $r^{2}$ \\
\hline$Y_{1}$ & Linear & 1.67 & 0.5741 & 0.4943 & 0.2519 & Remark \\
& Quadratic & 1.56 & 0.6953 & 0.5547 & -0.1852 & -0.1751 \\
& Special & 1.24 & 0.8526 & 0.7200 & - & suggest \\
& Cubic & 0.58 & 0.9870 & 0.9381 & 0.1175 & -0.4305 \\
$Y_{2}$ & Linear & 91.28 & 0.4058 & 0.2944 & 0.2692 & - \\
& Quadratic & 98.89 & 0.4333 & 0.1717 & - & Suggest \\
& Special & 65.86 & 0.8066 & 0.6326 & 0.9549 & - \\
\hline
\end{tabular}

Fitting model regression

Equation: $Y_{1}=24.40+0.75 A+1.18 B+1.45 C-1.14 \mathrm{AB}-0.52 \mathrm{AC}-0.89 \mathrm{BC}-0.19 A^{2}-1.09 B^{2}-1.68 C^{2}$

$Y_{2}=238.38+17.41 A-8.63 B-85.22 C-16.65 \mathrm{AB}+31.95 \mathrm{AC}-18.51 \mathrm{BC}-58.42 A^{2}-85.79 B^{2}+107.10 C^{2}$

Blood specimens were collected at the time of $0.1 \mathrm{~h}, 0.25 \mathrm{~h}$, $0.5 \mathrm{~h}, 1.0 \mathrm{~h}, 2.0 \mathrm{~h}, 4.0 \mathrm{~h}, 6.0 \mathrm{~h}, 8.0 \mathrm{~h}, 10.0 \mathrm{~h}, 12.0 \mathrm{~h}$, and $24.0 \mathrm{~h}$ after administration (22); $0.5 \mathrm{~mL}$ of blood sample of each animal was collected from the fundus veins into heparinized centrifuge tubes and was centrifuged at $5000 \mathrm{rpm}$ for $10 \mathrm{~min}$. The plasma kept at $-80^{\circ} \mathrm{C}$ until assay.

\section{Analytical Method for ZgI Quantification}

Agilent 1260 HPLC. The column was a Unitary $\mathrm{C}_{18}$ column $(250 \mathrm{~mm} \times 4.6 \mathrm{~mm}, 5 \mu \mathrm{m})$, the mobile phase was acetonitrilewater (32:68), the volume flow rate was $1 \mathrm{~mL} / \mathrm{min}$, the column temperature was $30^{\circ} \mathrm{C}$, the detection wavelength was $203 \mathrm{~nm}$, and the injection volume was $10 \mu \mathrm{L}$ (23).

\section{Statistical Analysis}

The data are presented as means \pm S.E.M. KolmogorovSmirnov's test was used to evaluate normality of the data distribution. Data was then analyzed by an independent $t$ test

\section{a}

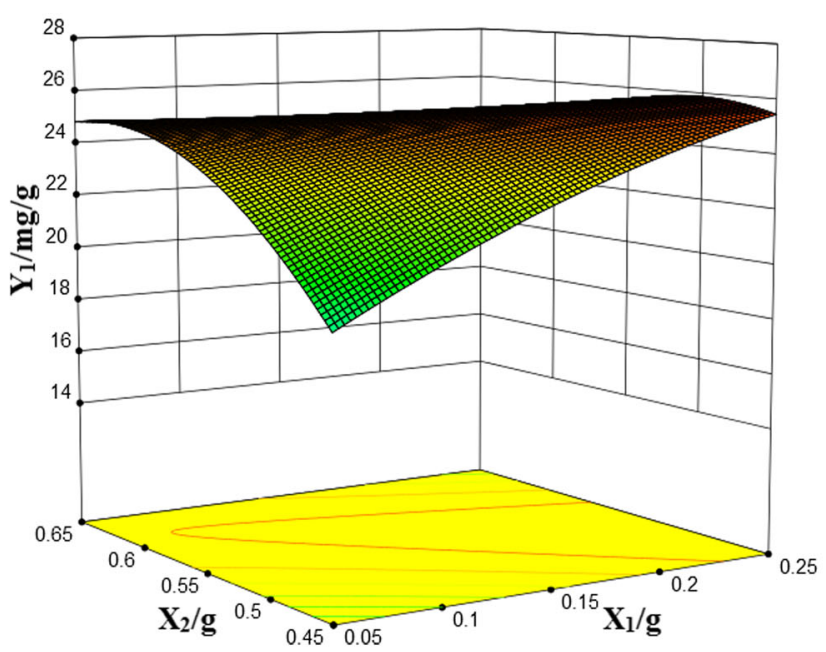

Fig. 3. Drug loading 3D stereogram (a) and 2D contour map (b) or a one-way ANOVA followed by Tukey's post hoc test. Statistical significance was considered at $p$ values $<0.05$.

\section{RESULTS}

\section{Solubility of ZgI in Different Excipients}

In order to increase the solubility of $\mathrm{ZgI}$ in SMEDDS, the solubility of $\mathrm{ZgI}$ in various excipients was investigated to select excipients with greater solubilization potential. The solubility of $\mathrm{ZgI}$ in various excipients is shown in Table I. The maximum solubility of $\mathrm{ZgI}$ in $\mathrm{mg} / \mathrm{g}$ was observed in Transcutol HP $(9.75 \mathrm{mg} / \mathrm{g})$, followed by Tween-20 (4.23 mg/g), Obleique CC497 (2.87 mg/g), and Oleic acid $(2.63 \mathrm{mg} / \mathrm{g})$. According to the results of saturated solubility, further research will be conducted on the excipients with greater solubilization potential.

\section{Optimization of Excipients for Preparation of SMEDDS}

Before using DoE, we should select the most appropriate oil phase by drawing a ternary phase diagram and further

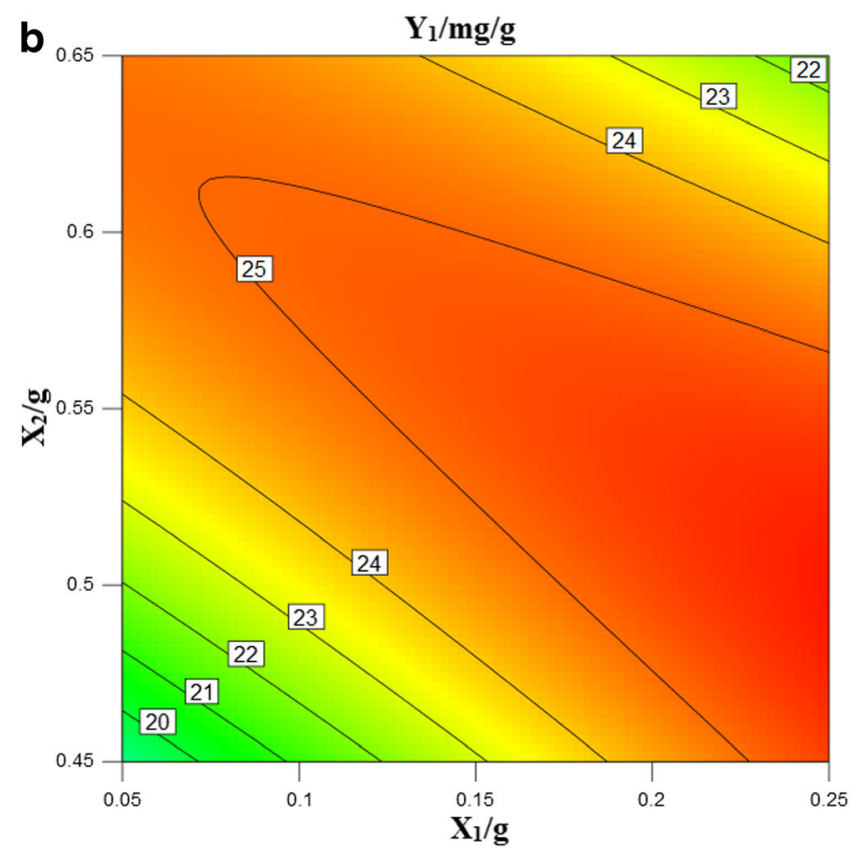


a

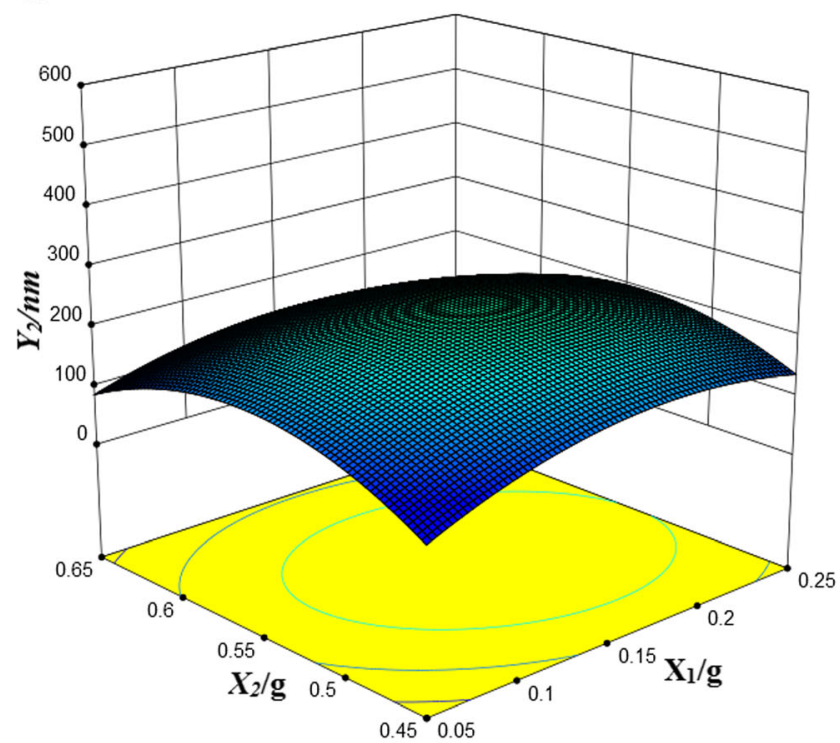

Fig. 4. Particle size 3D stereogram (a) and 2D contour map (b)

confirm the ratio of the prescription. The ternary phase diagram was constructed to identify the desired SMEDDS regions. Finally, the size of microemulsion area was calculated to determine which the best oil phase is. As shown in Fig. 2. It was found that the areas of monophasic transparent formulations using Oleic acid and Obleique CC497 were10.35 \pm 3.16 and $19.26 \pm 3.87 \%$ of the total phase diagram, respectively. The results suggested that Obleique CC497 created larger monophasic area in the phase diagrams. So Obleique CC497, Tween-20, and Transcutol $\mathrm{P}$ were used to make $\mathrm{ZgI}-$ SMEDDS.

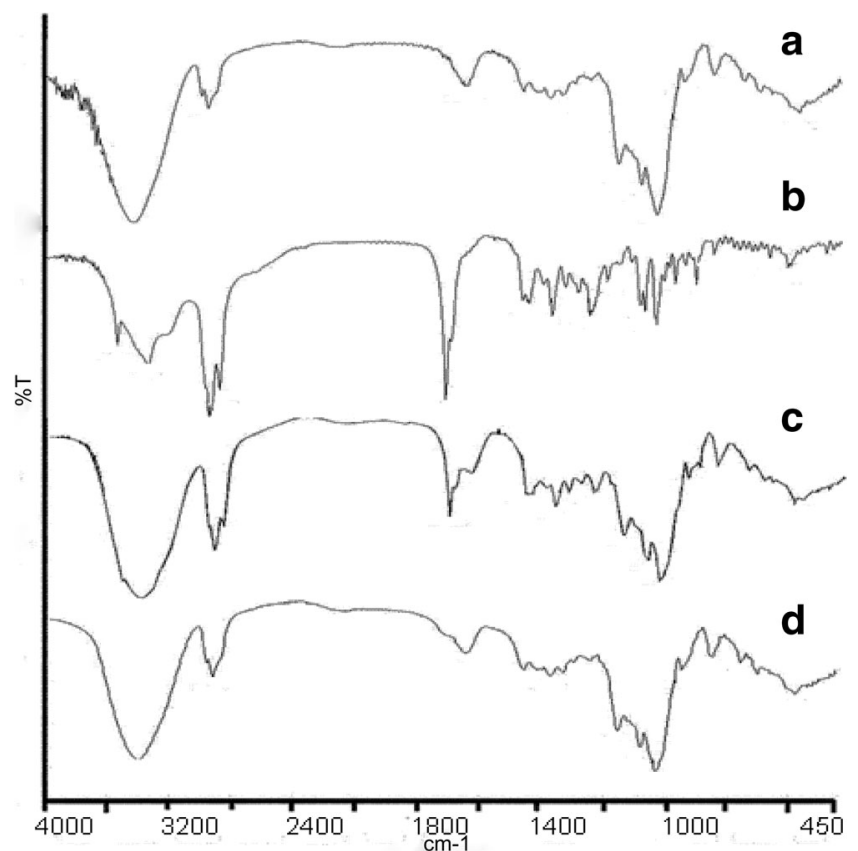

Fig. 5. The FTIR spectra of (a) SMEDDS, (b) ZgI, (c) physical mixture, (d) ZgI-SMEDDS

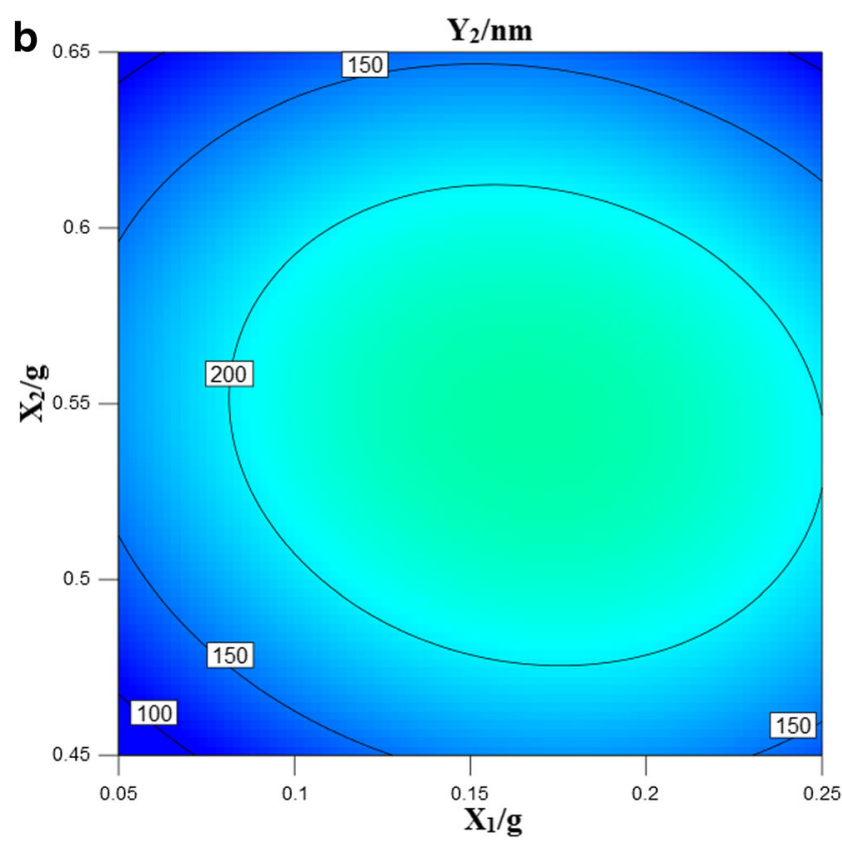

\section{D-Optimal Mixture Design}

The weight of Obleique CC497( $\left.X_{1} / \mathrm{g}\right)$, Tween-20 $\left(X_{2} / \mathrm{g}\right)$, and Transcutol $\mathrm{P}\left(X_{3} / g\right)$ was chosen as the factors; the drug loading rate $\left(Y_{1} / \mathrm{mg} \mathrm{g}^{-1}\right)$ and particle $\operatorname{size}\left(Y_{2} / \mathrm{nm}\right)$ were chosen as the evaluation index. The response data for all experimental runs of the D-optimal mixture design are shown in Table II. An analysis of variance (ANOVA) was used to estimate the significance of the effect of each variable and its interaction. Four kinds of mathematical models were used to perform regression fitting and analysis. The standard

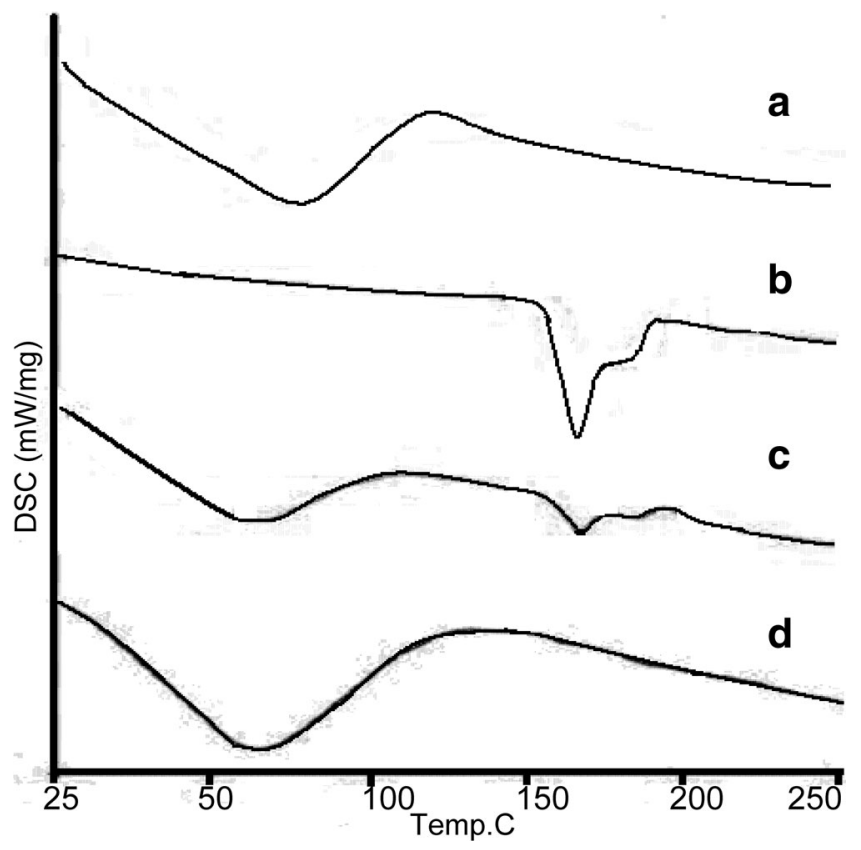

Fig. 6. The DSC thermograms of (a) SMEDDS, (b) ZgI, (c) physical mixture, (d) ZgI-SMEDDS 


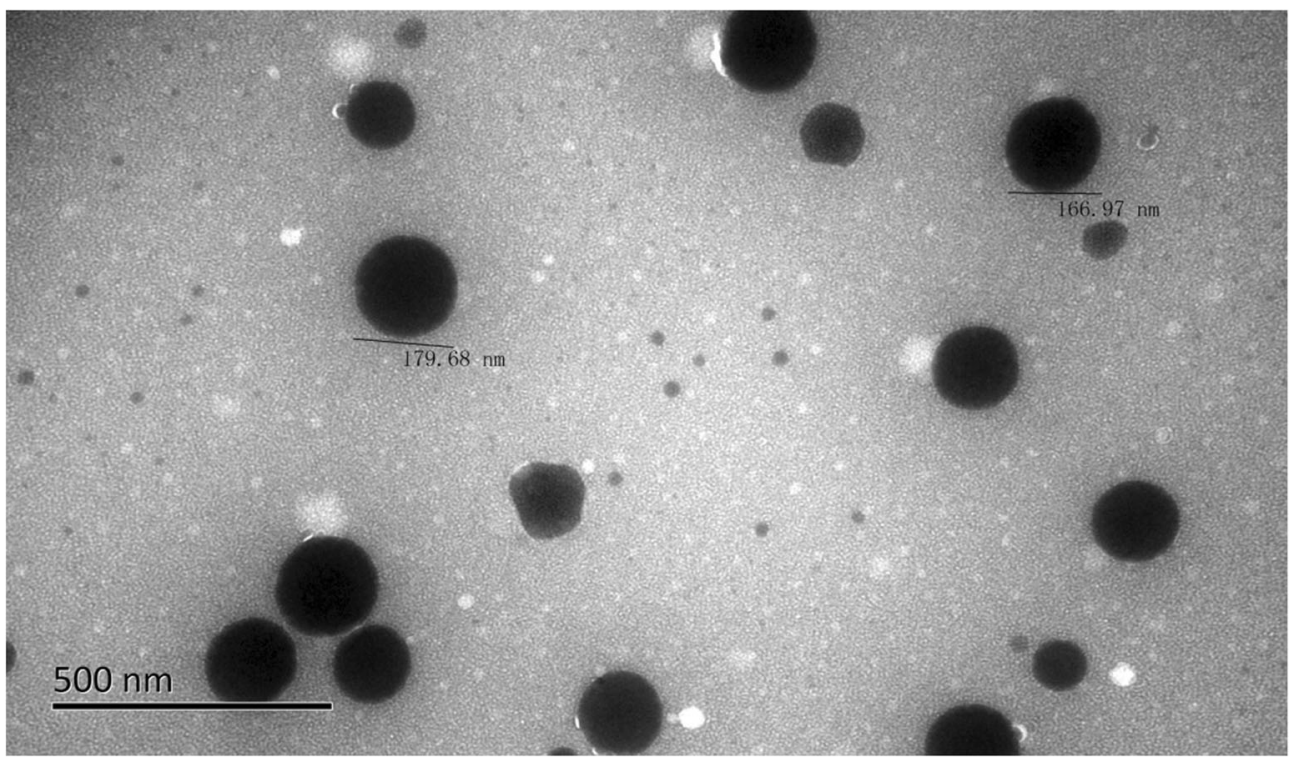

Fig. 7. Micromorphology of the ZgI-SMEDDS

variance, complex correlation coefficient, predictive compound correlation coefficient, and adjusted correlation coefficient of the regression model were used as comprehensive indicators to judge and select the best regression model among the four mathematical models. The results are shown in Table III.

Influence of Formulation Variables on Response $Y_{1}$ (Solubility of $\mathrm{ZgI}$ )

The positive sign in the polynomial regression equation indicates the synergy effect, and the negative sign indicates the antagonistic effect. In the special cube model that responds to $Y_{1}$, three factors alone (Transcutol HP, Obleique, Tween-20) have positive effects, of which Obleique has a significantly lower effect. The complex correlation coefficient of the $Y_{1}$ response value is higher, which indicated that the regression model was fitted well and the regression equation had a good representation and could accurately predict the actual situation. The 3D stereogram and 2D contour of $Y_{1}$ response values are shown in Fig. 3.
Influence of Formulation Variables on Response $Y_{2}$ (Droplet Size upon Dilution)

In the special cubic model response to $Y_{2}$ other than Obleique CC497, the remaining two factors alone have a negative effect on droplet size after dilution. That is, as the concentration increases, the droplet size decreases. The complex correlation coefficient of the $Y_{2}$ response value is higher, which indicated that the regression model was fitted well and the regression equation has a good representation and can accurately predict the actual situation. The 3D stereogram and 2D contour of $Y_{2}$ response values are shown in Fig. 4.

\section{Optimized Formulation Verification}

From the D-optimal mixture design result, we got the optimal formulation of SMEDDS, which was composed of CC497-Tween-20-Transcutol P (0.25:0.45:0.30). Then the optimized formulation was repeated three times. The polydispersity index of the prescription was less than 0.3 , so it could meet the stability requirements of the preparation.

Table IV. Stability Test Result of ZgI-Loaded SMEDDS $(\bar{x} \pm \mathrm{S}, n=3)$

\begin{tabular}{|c|c|c|c|c|}
\hline Month & Condition & Appearance & Drug content $(\%)$ & Particle size $(\mathrm{nm})$ \\
\hline 0 & $25^{\circ} \mathrm{C} 60 \%(\mathrm{RH})$ & Clear liquid & $100.02 \pm 0.16$ & $206.97 \pm 4.35$ \\
\hline 1 & & Clear liquid & $100.18 \pm 0.27$ & $207.11 \pm 3.54$ \\
\hline 2 & & Clear liquid & $100.23 \pm 0.19$ & $206.88 \pm 4.01$ \\
\hline 3 & & Clear liquid & $100.08 \pm 0.17$ & $208.15 \pm 4.75$ \\
\hline 0 & $40^{\circ} \mathrm{C} 75 \%(\mathrm{RH})$ & Clear liquid & $100.19 \pm 0.37$ & $207.08 \pm 5.61$ \\
\hline 1 & & Clear liquid & $100.42 \pm 0.36$ & $207.22 \pm 3.44$ \\
\hline 2 & & Clear liquid & $100.22 \pm 0.30$ & $209.16 \pm 3.08$ \\
\hline 3 & & Clear liquid & $100.11 \pm 0.42$ & $206.70 \pm 4.82$ \\
\hline
\end{tabular}




\section{Characterization of SMEDDS}

The optimal formulation was diluted 200 times with water in a volumetric flask under stirring conditions. The zeta potential, droplet size, and polydispersity index were measured with particle size analyzer (Mastersizer 3000, Malvern Panalytical Co, Ltd., UK). The average droplet size of SMEDDS was $207.92 \pm 2.13 \mathrm{~nm}$, the polydispersity index was $0.264 \pm 0.015$, and the zeta potential was $-38.84 \pm 0.18 \mathrm{mV}$.

\section{Result of ZgI-Excipients Compatibility Studies}

FTIR

The FTIR spectra of SMEDDS, ZgI, physical mixture, and ZgI-SMEDDS are presented in Fig. 5. As shown in the spectrum of SMEDDS (Fig. 5a), there are absorption peaks at $3421 \mathrm{~cm}^{-1}$ (for $\nu \mathrm{O}-\mathrm{H}$ stretching vibration), $2932 \mathrm{~cm}^{-1}$ (for $\nu \mathrm{C}-\mathrm{H}$ stretching vibration), and $1157 \mathrm{~cm}^{-1}$ and $1083 \mathrm{~cm}^{-1}$ (for $\nu \mathrm{C}-\mathrm{H}, v \mathrm{C}-\mathrm{O}$ stretching vibration). Compared to SMEDDS, $\mathrm{ZgI}$ had a group of $\nu \mathrm{C}=\mathrm{O}$, so its spectrum (Fig. 5b) showed a characteristic absorption peak of $\nu \mathrm{C}=\mathrm{O}$ at $1715 \mathrm{~cm}^{-1}$ (for $\nu \mathrm{C}=\mathrm{O}$ stretching vibration). Except the characteristic absorption peak of $\nu \mathrm{C}=\mathrm{O}$, the spectrum of physical mixture (Fig. 5c) was approximately similar to that of SMEDDS. In contrast, the characteristic absorption peak of $\nu \mathrm{C}=\mathrm{O}$ has disappeared from the spectrum of the ZgI-SMEDDS (Fig. $5 \mathrm{~d})$. Therefore, the characteristic absorption peak of $\nu \mathrm{C}=\mathrm{O}$ at $1715 \mathrm{~cm}^{-1}$ allowed the distinction between physical mixture and $\mathrm{ZgI}-\mathrm{SMEDDS}$. Accordingly, we could conclude that $\mathrm{ZgI}$ was dissolved in the SMEDDS and the group of $\nu \mathrm{C}=\mathrm{O}$ might be involved in the solution, leading to the absence of $\nu \mathrm{C}=\mathrm{O}$ characteristic absorption peak.

$D S C$

DSC thermograms are shown in Fig. 6. The thermogram of SMEDDS (Fig. 6a) illustrated a very broad endothermic effect, which attains a maximum $86^{\circ} \mathrm{C}$, and $\mathrm{ZgI}$ is characterized by a sharp melting endotherm at $175^{\circ} \mathrm{C}$ (Fig. 6b). The DSC thermogram of physical mixture (Fig. 6c) displays two peaks: a broad endotherm at $86^{\circ} \mathrm{C}$ followed by the endothermal melting peak at $175^{\circ} \mathrm{C}$ characteristic of $\mathrm{ZgI}$. In the meanwhile, there is a noticeable difference between physical mixture and ZgI-SMEDDS. The characteristic peak of $\mathrm{ZgI}$ is absent in the DSC thermogram of inclusion complex (Fig. 6d), which confirms the presence of $\mathrm{ZgI}$ in an amorphous form.

\section{TEM}

ZgI-SMEDDS was appropriately diluted, and it was revealed by transmission electron microscopy that the SMEDDS microemulsion was spherical and uniform in size. The TEM image of ZgI-SMEDDS is shown in the Fig. 7.

\section{Stability of ZgI-Loaded SMEDDS}

The stability data of ZgI-loaded SMEDDS was shown in Table IV. From Table IV, we can conclude that the ZgISMEDDS could keep stable at least 3 months without

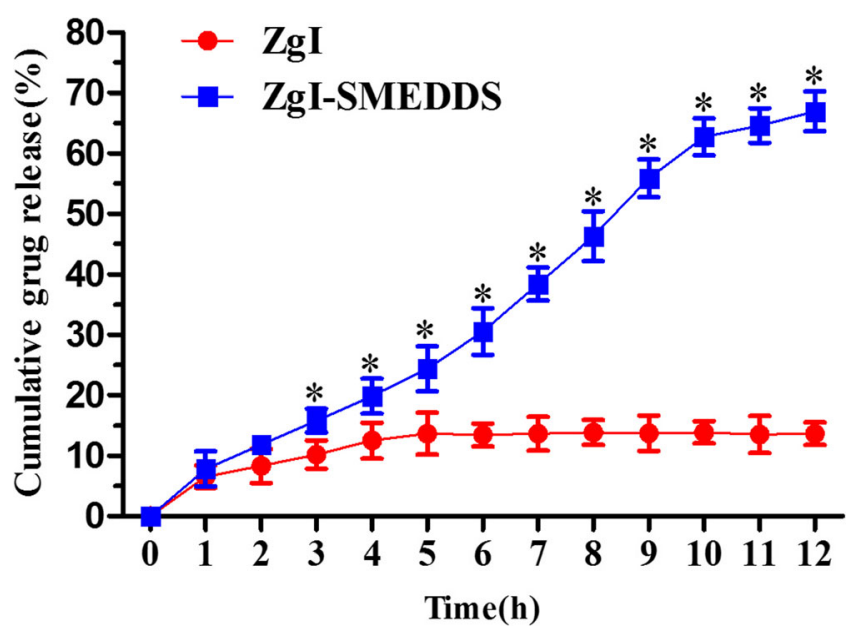

Fig. 8. The cumulative drug release of the ZgI-SMEDDS and ZgI. Compared with the $\mathrm{ZgI}$ group, $* P<0.05$

sediment of $\mathrm{ZgI}$ in stability chamber. On the two specified storage conditions $\left(25^{\circ} \mathrm{C} / 60 \% \mathrm{RH}\right.$ and $\left.40^{\circ} \mathrm{C} / 75 \% \mathrm{RH}\right)$, the emulsion was clear liquid all the time, drug content did not decrease, and the particle size did not change.

\section{In Vitro ZgI Release from SMEDDS}

The in vitro cumulative release profile of $\mathrm{ZgI}$ from $\mathrm{ZgI}$ SMEDDS is shown in Fig. 8. The in vitro cumulative release of $\mathrm{ZgI}$ from D-SMEDDS was found to be $78.96 \pm 2.83 \%$ within $12 \mathrm{~h}$. Compared with the $\mathrm{ZgI}, \mathrm{ZgI}-\mathrm{SMEDDS}$ had a quicker release rate, which showed that the release of $\mathrm{ZgI}$ had been greatly improved by the SMEDDS.

\section{In Situ Single Pass Intestinal Perfusion}

SD rats were used to study the in situ intestinal perfusion of $\mathrm{ZgI}$ and $\mathrm{ZgI}$-SMEDDS. The apparent permeability coefficients $\left(P_{\text {app }}\right)$ of the $\mathrm{ZgI}$ and the ZgI-SMEDDS were $1.04 \pm 0.02 \times$ $10^{-4} \mathrm{~cm} / \mathrm{s}$ and $5.71 \pm 0.24 \times 10^{-4} \mathrm{~cm} / \mathrm{s}$, respectively $(P<0.05)$. The drug absorption percentage $(A \%)$ of the $\mathrm{ZgI}$ and the $\mathrm{ZgI}-$ SMEDDS were $1.04 \pm 0.02 \times 10^{-4} \mathrm{~cm} / \mathrm{s}$ and $5.71 \pm 0.24 \times$ $10^{-4} \mathrm{~cm} / \mathrm{s}$, respectively $(P<0.05)$. The absorption rate constant $\left(K_{\mathrm{a}}\right)$ of the $\mathrm{ZgI}$ and the ZgI-SMEDDS were $1.04 \pm 0.02 \times$ $10^{-4} \mathrm{~cm} / \mathrm{s}$ and $5.71 \pm 0.24 \times 10^{-4} \mathrm{~cm} / \mathrm{s}$, respectively $(P<0.05)$. The $P_{\text {app }}, A \%$, and $K_{\mathrm{a}}$ of SMEDDS were significantly increased compared to those of the $\mathrm{ZgI}$.

Table V. Effect of ZgI-SMEDDS on WBC of Myelosuppression Mice $(\bar{x} \pm \mathrm{S}, n=10)$

\begin{tabular}{llll}
\hline Groups & Number & Dosage $\left(\mathrm{mg} \mathrm{kg}^{-1}\right)$ & WBC $\left(\times 10^{9}\right)$ \\
\hline Normal & 10 & 10 & $5.31 \pm 1.8^{* \Delta}$ \\
Model & 10 & 10 & $2.23 \pm 0.32$ \\
ZgI & 10 & 10 & $2.81 \pm 0.15$ \\
ZgI-SMEDDS & 10 & 10 & $4.59 \pm 0.27^{* \Delta}$ \\
\hline
\end{tabular}

Compared with the model group, $* P<0.05$, $* * P<0.01$; compared with the $\mathrm{ZgI}$ group, ${ }^{\Delta} \mathrm{P}<0.05,{ }^{\Delta \Delta} \mathrm{P}<0.01$. $\mathrm{ZgI}$ ziyuglycoside I, $\mathrm{ZgI}$ SMEDDS ziyuglycoside I-self-microemulsifying drug delivery system, $W B C$ white blood cell 


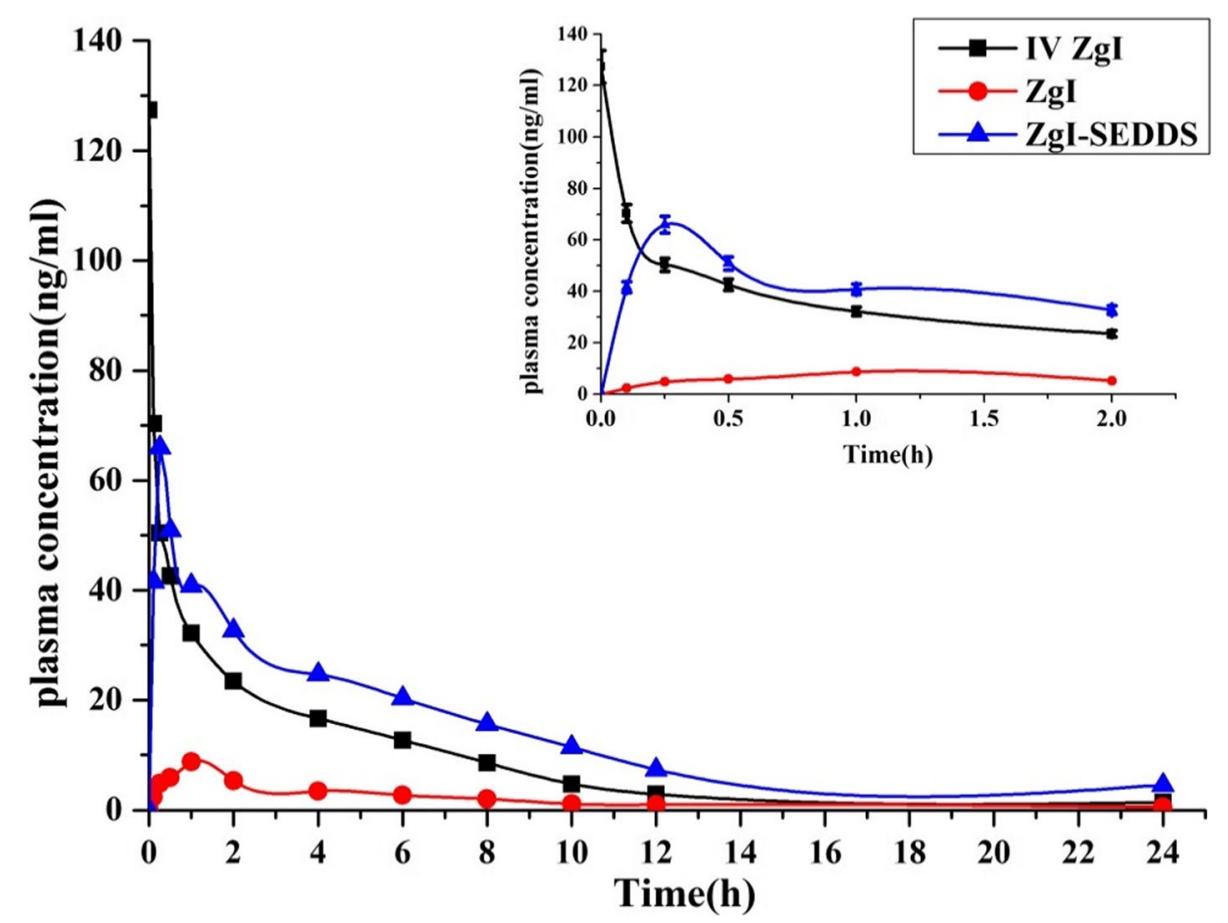

Fig. 9. Mean plasma concentration-time curves of $\mathrm{ZgI}$ after i.v of a single dose of $2 \mathrm{mg} / \mathrm{kg}$ of $\mathrm{ZgI}$ Tween-20 solution, oral administration of a single dose of $20 \mathrm{mg} / \mathrm{kg}$ of $\mathrm{ZgI}$ Tween-20 solution, and equivalent dose of oral ZgI-SMEDDS. Picture on the top right corner was the plasma concentration-time curves for $0-2 \mathrm{~h}$ duration (mean \pm SEM, $n=6$ /group)

\section{In Vivo Activity Study}

Kunming (KM) mice were used to study the in vivo activity of raising white blood cells (WBCs) of ZgI SMEDDS. Mice were injected with cyclophosphamide $\left(200 \mathrm{mg} \mathrm{kg}^{-1}\right)$ intraperitoneally to make myelosuppression model. Compared with the normal group, the WBC count in model group was markedly decreased $(P<0.05)$ and the WBC count in $\mathrm{ZgI}$ group was markedly decreased $(P<0.05)$ too. Compared with the model group, the WBC count of $\mathrm{ZgI}-$ SMEDDS group was significantly increased $(P<0.05)$; compared with $\mathrm{ZgI}$ group, the WBC count of $\mathrm{ZgI}-\mathrm{SMEDDS}$ group was significantly increased $(P<0.05)$. The effect of each test group on the number of peripheral white blood cells in mice is shown in the Table V.

\section{In Vivo Pharmacokinetic Study}

The mean plasma concentration-time curve of $\mathrm{ZgI}$ after i.v of a single dose of $2 \mathrm{mg} / \mathrm{kg}$ (equivalent to free $\mathrm{ZgI}$ ) of $\mathrm{ZgI}$ Tween-20 solution, oral administration of a single dose of $20 \mathrm{mg} / \mathrm{kg}$ (equivalent to free $\mathrm{ZgI}$ ) of $\mathrm{ZgI}$ Tween-20 solution, and equivalent dose of oral ZgI-SMEDDS were shown in Fig. 9. The $C_{\max }$ of oral $\mathrm{ZgI}-S M E D D S$, oral $\mathrm{ZgI}$, and i.v $\mathrm{ZgI}$ were found to be $65.95 \pm 8.74,8.75 \pm 1.21$, and $127.3 \pm 26.87 \mathrm{ng} / \mathrm{mL}$, respectively. The blood concentration of $\mathrm{ZgI}$ was dramatically elevated by SMEDDS at $30 \mathrm{~min}$ after administration. The pharmacokinetic parameters were calculated using anoncompartment model and were summarized in Table VI. Compared with the $\mathrm{ZgI}$ group, the $\mathrm{AUC}_{0-\mathrm{t}}$ and $C_{\max }$ of the ZgI-SMEDDS were markedly increased $(P<0.05)$. What's

Table VI. PK Parameters of ZgI (i.v and p.o) and ZgI-SMEDDS (p.o) $(\bar{x} \pm S, n=6)$

\begin{tabular}{|c|c|c|c|c|}
\hline \multirow[t]{2}{*}{ PK parameters } & \multirow[t]{2}{*}{ Units } & \multirow[t]{2}{*}{ i.v $\mathrm{ZgI}$} & \multicolumn{2}{|c|}{ ig (intragastrical administration) } \\
\hline & & & $\mathrm{ZgI}$ & ZgI-SMEDDS \\
\hline Dose & $\mathrm{mg} / \mathrm{kg}$ & 2 & 10 & 10 \\
\hline$V_{\mathrm{d}}$ & $\mathrm{L} / \mathrm{kg}$ & $189.34 \pm 36.47$ & $2983.4 \pm 289.27$ & $1214.69 \pm 143.57 *$ \\
\hline $\mathrm{CL}$ & $\mathrm{L} \min ^{-1} \mathrm{~kg}^{-1}$ & $8.37 \pm 1.05$ & $91.51 \pm 11.28$ & $25.87 \pm 3.56^{*}$ \\
\hline $\mathrm{AUC}_{0-\mathrm{t}}$ & $\mathrm{ng} \min \mathrm{mL}^{-1}$ & $246.55 \pm 28.43$ & $78.12 \pm 12.46$ & $270.52 \pm 37.18^{*}$ \\
\hline MRT & $\mathrm{h}$ & $5.42 \pm 0.65$ & $3.26 \pm 0.18$ & $6.55 \pm 0.26^{*}$ \\
\hline$C_{\max }$ & $\mathrm{ng} \mathrm{mL} \mathrm{L}^{-1}$ & $127.3 \pm 26.87$ & $8.75 \pm 1.21$ & $65.95 \pm 8.74$ \\
\hline$T_{1 / 2}$ & $\mathrm{~h}$ & $12.67 \pm 1.33$ & $19.32 \pm 4.75$ & $19.2 \pm 5.21 *$ \\
\hline$T_{\max }$ & $\mathrm{h}$ & 0.01 & 0.25 & 1 \\
\hline$F$ & $\%$ & - & $3.16 \pm 0.89$ & $21.94 \pm 4.67$ \\
\hline
\end{tabular}


important is that the oral ZgI-SMEDDS led to a 6.94-fold higher absolute bioavailability $(21.94 \pm 4.67) \%$ than $\mathrm{ZgI}$ $(3.16 \pm 0.89) \%$. We also find that the mean resident time (MRT) was increased and clearance (CL) was decreased, which implied that the SMEDDS may prolong the retention time of $\mathrm{ZgI}$ in vivo and distribute it in different tissues.

\section{CONCLUSION}

We have successfully developed optimal formulations of the ZgI-loaded SEDDS, which can increase the solution rate, solubility, and bioavailability of $\mathrm{ZgI}$. The new emulsion formulations are a promising alternative to oral delivery of water-insoluble drugs like $\mathrm{ZgI}$. Our studies illustrated that SMEDDS containing Obleique CC497, Tween-20, and Transcutol HP with a ratio of 0.25/0.45/0.30 was showed to increase solubility and dissolution rate of $\mathrm{ZgI}$ and it may remain stable at least 3 months under limited conditions. The SMEDDS had a faster release rate than plain $\mathrm{ZgI}$. In vivo evaluation, we found that SMEDDS showed nearly a sevenfold greater absorption of $\mathrm{ZgI}$ compared to the same oral dose of the plain ZgI Tween-20 solution. Finally, the SMEDDS can significantly improve the efficacy of $\mathrm{ZgI}$ to increase WBCs. Thus, our studies indicated that the new self-microemulsifying system could be a valuable drug delivery to $\mathrm{ZgI}$ with improved oral bioavailability and biological activity.

\section{FUNDING INFORMATION}

This work was supported by the Guizhou Provincial Research Foundation for Basic Research, China (Grant No. Qiankehejichu[2018]1426), Union Foundation of Zunyi Science and Technology Board, and Zunyi Medical University (Grant No. Zunshikeheshezi[2017]19).

\section{COMPLIANCE WITH ETHICAL STANDARDS}

The experimental protocol was approved by the Animal Ethics Committee for animal experimentation of Zunyi Medical University (Ethic numbers (2018)2-030).

Open Access This article is distributed under the terms of the Creative Commons Attribution 4.0 International License (http://creativecommons.org/licenses/by/4.0/), which permits unrestricted use, distribution, and reproduction in any medium, provided you give appropriate credit to the original author(s) and the source, provide a link to the Creative Commons license, and indicate if changes were made.

Publisher's Note Springer Nature remains neutral with regard to jurisdictional claims in published maps and institutional affiliations.

\section{REFERENCES}

1. Bazan JG, Luxton G, Mok EC, et al. Normal tissue complication probability modeling of acute hematologic toxicity in patients with squamous cell carcinoma of the anal canal treated with definitive chemoradiotherapy[J]. Int J Radiat Oncol. 2011;81(2):S126.

2. Zhu Y, Wang L, Yang Z, et al. Hematopoietic effects of paeoniflorin and albiflorin on radiotherapy-induced myelosuppression mice [J]. Evid-Based Complement Alternat Med. 2016;15:5789381.
3. Yi Y, Qibin S, Xiaotao X, et al. Infusion of allogeneic umbilical cord blood hematopoietic stem cells in patients with chemotherapyrelated myelosuppression[J]. ExpTher Med. 2014;8(6):1946-50.

4. Dai LM, Xiong YA, Yang M, et al. Protective effects of dioscin saponins on mice myelosuppression induced by cyclophosphamide. Nat Prod Res Dev. 2016;28(6):852-9.

5. Su ZT, Liu Y, Yang M, et al. Optimization of flash extraction process of saponins from Radix Scutellariae by Box-Behnken design. CHM. 2012;43(3):501-4.

6. Gao XP, Wu JM, Zou WJ, et al. Screening of the active fractions from Sanguisorba officinalis promoting hematopoiesis $[\mathrm{J}]$. CJNM. 2006;4(2):137-40.

7. Xiong YA, Zou Y, Wang S, et al. Promotion of ziyuglycoside I on white blood cells by autophagy pathway[J]. CHM. 2018;49(14):3350-6.

8. Zou WJ, Liu F, Wu JM, et al. Study on the proliferation of hematopoietic cells induced by total saponins from Dioscorea paniculata. CHM. 2012;43(5):929-33.

9. Dai YP, Gao XP, Wu JM, Etal. Effect of mantle total saponins on proliferation, differentiation and related receptor expression of megakaryocyte progenitor cells. China J Chin Mater Med, 2014, 39(9): 1685-1689.

10. Samatha A, Kumar GA, Reddy DS. Self-microemulsifying drug delivery systems: an attractive strategy for enhanced therapeutic profile. Int S R N. 2014;2014:1-11.

11. Liu C, Lv L, Huang X, et al. Self-nanoemulsifying drug delivery system of tetrandrine for improved bioavailability: physicochemical characterization and pharmacokinetic study [J]. Biomed Res Int. 2018;2018:6763057.

12. Aws A, Mohsin K, Fars K A,etal. Role of alternative lipid excipients in the design of self-nanoemulsifying formulations for fenofibrate: characterization, in vitro dispersion, digestion and ex vivo gut permeation studies. Front Pharmacol 2018; 9: 1219.

13. Valicherla GR, Dave KM, Syed AA, et al. Formulation optimization of docetaxel loaded self-emulsifying drug delivery system to enhance bioavailability and anti-tumor activity. Sci Rep. 2016;6:1-11

14. Anayatollah S, Behzad SMZ, Ali Asghar H, et al. Design and evaluation of self-emulsifying drug delivery system (SMEDDS) of carvedilol to improve the oral absorption. Jundishapur J Nat Pharm Prod. 2014;9(3):e16125.

15. Samatha A, Kumar GA, Reddy DS. Self-microemulsifying drug delivery systems: an attractive strategy for enhanced therapeutic profile. Int Scholarly Res Notices. 2014;12(6):1-11.

16. Seo YG, Kim DH, Ramasamy T, Kim JH, Marasini N, Oh YK, et al. Development of docetaxel-loaded solid selfnanoemulsifying drug delivery system (SNEDDS) for enhanced chemotherapeutic effect. Int J Pharm. 2013;452(1-2):412-20.

17. Yan YD, Marasini N, Choi YK, Kim JO, Woo JS, Yong CS, et al. Effect of dose and dosage interval on the oral bioavailability of docetaxel in combination with a curcumin self-emulsifying drug delivery system (SMEDDS). Eur J Drug Metab Pharmacokinet. 2012;37(3):217-24.

18. Kalepu S, Nekkanti V. Insoluble drug delivery strategies: review of recent advances and business prospects. Acta Pharm Sin B. 2015;5(5):442-53.

19. Lan WU, Wei HE, Zhao JH, Etal. Self-microemulsifying drug delivery system (SMEDDS) for a novel medicative compound against depression: physicochemical property and in vitro release. JPR, 2015,12(5): 312-318.

20. Myoung KB, Jong HL, Gye WL, et al. Self-microemulsifying drug-delivery system for improved oral bioavailability of pranlukast hemihydrate: preparation and evaluation. Int $\mathrm{J}$ Nanomedicine. 2013;8:167-76.

21. Tang TT, Hu XB, Liao DH, et al. Mechanisms of microemulsion enhancing the oral bioavailability of puerarin: comparison between oil-in-water and water-in-oil microemulsions using the single-pass intestinal perfusion method and a chylomicron flow blocking approach. Int J Nanomedicine. 2013;2013(Issue 1):4415-26.

22. Patel JR, Barve KH. Intestinal permeability of lamivudine using single pass intestinal perfusion. Indian $\mathrm{J}$ Pharm Sci. 2013;74(5):478-81.

23. Xiong YA, Yang M. Effects of sanguisorba tannins and saponins compatibility on pharmacokinetic parameters of catechin. China J Chin Mater Med. 2016;41(19):3661-7. 